\title{
A Bachelor's Degree in Electrical Engineering for Non-Traditional Students
}

\author{
Online Survey of the Target Group as Input for Conception \\ http://dx.doi.org/10.3991/ijep.v3i3.2770 \\ C. Böhmer ${ }^{1}$, N. Roznawski ${ }^{1}$, H. Meuth ${ }^{2}$ and E.M. Beck-Meuth ${ }^{1}$ \\ ${ }^{1}$ Hochschule Aschaffenburg, Aschaffenburg, Germany \\ ${ }^{2}$ Hochschule Darmstadt, Darmstadt, Germany
}

\begin{abstract}
A blended-learning Bachelor's degree in electrical engineering is designed within the program "Upward mobility through academic training". A questionnaire concerning learning intentions and needs returned by 144 potential non-traditional students was evaluated in the conception phase. Additionally, regional companies of which 24 returned a questionnaire were asked what they expected from the graduates. The consequences for the design of the program are discussed.
\end{abstract}

Index Terms - bachelor's degree, blended learning, distance learning, education, e-learning, electrical engineering, nontraditional, online survey, questionnaire, students, study program

\section{UPWARD MOBILITY FOR ACADEMIZATION}

In Germany, the fraction of high-school graduates taking up studies at a university is still below that of other OECD countries. Thus, German government made an effort to open universities to non-traditional students bringing forth a program line "Upward mobility through academic training" [1]. Within this initiative the Universities of Applied Sciences of Darmstadt (state Hesse) and Aschaffenburg (state Bavaria) won a grant to design a distance-learning Bachelor's program in electrical engineering for non-traditional students. The project is named "Open e-University" because a formal high-school diploma is no prerequisite for enrollment in this bachelor's degree signaling openness, and electronic media play an important role in distance learning. In this case nontraditional students belong to the workforce in industry who is qualified through their jobs, e.g. technicians or skilled workers with a qualification concluding vocational training. The program is also open to students with a regular university admission who are time bound for other reasons, e.g. care for the elderly. However, the main goal of this project is offering people employed in the field of electrical engineering or technology to deepen their qualification and reach a Bachelor's degree without having to drop out of their jobs. Therefore, a special program adapted to the needs and circumstances of this target group is planned [2]. In order to get more information about the prospective students an online survey was initiated. Since the students of the target group will be employed with companies, regional enterprises were systematically asked what they expected from the graduates. Furthermore, experience with distance-learning was helpful to design the new study program.

\section{EXPERIENCES WITH A DISTANCE-LEARNING MASTER'S IN ELECTRICAL ENGINEERING}

The Universities of Applied Sciences of Aschaffenburg and Darmstadt have experience with distance-learning programs: Since 2007 they have been offering a joint distance-learning Master's program in electrical engineering, together with the Centre for Distance Teaching and Learning at Universities of Applied Sciences (ZFH) [3]. The three-year part-time program is organized in modules with a blended-learning concept. Self-study and face-to-face learning are intertwined: on the one hand students learn on their own at home or often while commuting. In this phase they stay in contact with teachers and fellow students by electronic means. On the other hand they physically meet in the classroom at university for lectures, labs, and courses. Special learning material is provided by teaching staff. An internal survey among the master's students showed that the students get along quite well with this teaching and learning concept [4]. Furthermore, non-traditional students without a Bachelor's degree were directly admitted to the Master's program in an experimental setting. Valuable insights could be gained for this clientele [5]. Therefore the existing distance-learning Master's program has been regarded as a best-practice example and served as a basis for the design of the Bachelor's program.

\section{INPUT FOR BACHELOR'S STUDY PROGRAM}

\section{A. Online Survey}

In order to get more information about the prospective students and especially their needs, an online survey has been conducted with the tool EvaSys. The online survey pursued different goals. One reason for starting the survey was to learn about the career plans of the target group and to find out whether they were interested in further education and training. Also, they were asked which kind of support they needed for being able to study on top of their employment. Since the intended study program is based on a blended-learning concept supported by e-learning, the target group was furthermore asked about their attitude towards online-based learning offerings and the internet. Altogether the survey dealt with the following aspects of the target group:
a) Satisfaction with their current situation
b) Their current working relationship
c) Their career plans 
PAPER

A BACHELOR'S DEGREE IN ELECTRICAL ENGINEERING FOR NON-TRADITIONAL STUDENTS

d) Their plans for further studies and education

e) Desired support for studying and individual requirements

f) Personal data

Most recently, results of an empirical study on nontraditional students in engineering have been published by Jürgens and Zinn, pointing out that there is a shortage of data regarding these students [6].

\section{B. Target Group of the Survey}

Non-traditional students will be the main target group of the new study program. Primarily we expect technicians, master craftsmen and skilled workers qualified in the field of electrical engineering or technology to be attracted by the program. Technical specialists having undergone vocational training after a high-school diploma (for traditional university admission) also belong to our target group. In order to reach the main group of interest, different institutions were asked for distribution of the online survey. The following institutions supported the online-survey:

- Technicians' forum (www.techniker-forum.de)

- Chambers of Industry and Commerce in Hesse, Bavaria, Baden-Wuerttemberg, and Rhineland Palatina

- Chambers of Crafts in these states

They sent the link of the online survey to their students respectively to their recent graduates by electronic mail.

\section{Participants}

Altogether $N=144$ persons $(94.3 \%$ male, $5.7 \%$ female) participated in the online survey over a period of two months (July 25th through September 25th 2012). Their ages range from 15 years to 30 and above: 15 to 20 years, $23.1 \%$; 21 to 30 years, $50.3 \%$; 30 years and above $26.6 \%$. Most of the participants $(56.3 \%)$ graduated from school with a general certificate of secondary education ("Mittlere Reife"), $20.8 \%$ with an entrance qualification for studying at a University of Applied Sciences and 6.9 $\%$ with a general qualification for university entrance. The remaining participants graduated from schools with lower qualifications. $31.3 \%$ are employed with firms that have up to 50 employees, $43.1 \%$ are employed with big firms having more than 500 employees. These are they major industrial sectors from which our students could be recruited. Firms with a number of employees between 51 and 500 play a minor role as employer. More than half of the respondents live within a distance of $100 \mathrm{~km}$ from Darmstadt respectively Aschaffenburg, a further $22.4 \%$ within a distance of up to $200 \mathrm{~km}$. In conclusion: three quarters of the respondents can reach the two universities in the Rhine-Main area within two to three hours.

\section{Results - Current Situation of the Participants}

As to their "current situation" $69.7 \%$ of the participants had finished their apprenticeship. More than $98 \%$ of those had received their degree by a Chamber of Crafts or a Chamber of Industry and Commerce. The survey identified numerous types of apprenticeships like electronic technicians for facilities engineering, infrastructure, industry, communication and information technology, machinery and drive technology. A high percentage of the participants $(95.8 \%)$ work at a company and about $78.3 \%$ have more than two years of working experience. Furthermore the participants were asked whether they were satisfied with their current working situation: Only $11.3 \%$ agreed, $49.3 \%$ disagreed. Overall two thirds would have liked to pursue further training and education after having finishing their apprenticeship. The main reasons not to do so were lacking financial resources $(42.4 \%)$ and family obligations $(19 \%)$.

\section{E. Results-Career Plans}

Online-survey results showed that career plans play an important role for the participants. The vast majority of them are interested in getting ahead with their career. Two thirds of the respondents stated that the job profile of an engineer has a high reputation for them. The majority of the questioned people (79.2\%) agree with the statement that an occupational change within the next years is a desirable goal. They are furthermore aware of the fact that a higher education level is important for their career advancement: $86.7 \%$ of the participants think that a higher education level is useful for their professional development. Due to a higher education level they see better chances to stay in their jobs or to find a job in the future $(74.1 \%)$. However, the various certificates - master craftsman, technician or Bachelor's degree - have different job potential for them. Only $28.7 \%$ of the participants believe that they will have better chances on the job market with a master craftsman degree. $55.6 \%$ of the questioned people agree with the statement that they will have better chances on the job market with a technician's degree, whereas $79.9 \%$ believe that this is true for an academic Bachelor's degree. With an academic degree respondents furthermore associate tasks at work which are more interesting and multifarious. The latter findings are indicators for the driving forces of upward mobility.

\section{F. Plans for Studying and Further Education}

For most of the prospective students starting a degree course or further education is only possible if they can uphold their jobs. Only $17.4 \%$ would leave their current or a future job in order to study. The respondents are well aware of the situation that studying besides a regular job leads to a higher workload and stress level: Nevertheless $61.8 \%$ of the questioned people think about studying. Furthermore the persons were asked if they would pay for studying. The results for this question are mixed. $36.1 \%$ are prepared to pay for degree courses, $42.4 \%$ are not sure, and $21.5 \%$ don't want to pay for it. Since being employed while studying is a demanding situation, we asked the target group if they expect their employer to support the idea of further training for a higher qualification. The results are also mixed. $39.2 \%$ believe that they would obtain support by their employers, $20.3 \%$ don't. About $40.6 \%$ of the questioned people are not sure whether they would obtain support. We were interested in the reasons which prevent prospective students from taking up a degree course. Various answers were given: lack of support from employers, problems due to financial reasons or family situation, too little time for studying or studying is too much theory. Survey results indicate that the most important factors are monetary problems and family obligations $(50.7 \%)$, followed by "too little time to study" (33.3\%). Less important were the items phrased "lack of support by employers" (25\%) and "studying is too much theory; I prefer to work in practice" $(22.9 \%)$. 
PAPER

A BACHELOR'S DEGREE IN ELECTRICAL ENGINEERING FOR NON-TRADITIONAL STUDENTS

\section{G. Support for Prospective Students and Personal Requirements}

In order to get more information about the target group, they were asked what would help them to make a decision in favor of studying and which support would be helpful while they were studying. More than three quarters $(77.8 \%)$ prefer electronic information in order to make a decision in favor of studying. $56.9 \%$ of the questioned people are interested in free trial lectures at the university. $49 \%$ like to have printed leaflets, and $42.4 \%$ are interested in getting information directly at the university. From these answers a strategy for marketing can be deducted.

Concerning the support during their future course of studies, the target group expressed different preferences. The item "suitable learning materials" obtained highest agreement with $87.5 \%$. Besides, they wish preparatory courses which prepare them for their field of study (70.1\%). "Mentoring" (64.6\%), "sufficient contact with teaching staff" $(47.9 \%)$, "videos for preparation and postprocessing" (45.8\%), and "student projects together with company" (45.8\%) were regarded as other helpful measures to support successful studies.

\section{H. E-learning and Computer Literacy}

E-learning being an important point in distance learning the target group was asked about their attitude towards internet-based learning possibilities and their knowledge about the use of computers and internet. Therefore different items concerning online learning were included. It is obvious that the target group is very computer literate, although many persons - according to their reported age do not belong to the generation of digital natives yet. More than three quarters of the respondents find "online exchange with other students" very attractive. More than $70 \%$ wish to have "online exchange with teachers". $84 \%$ of the questioned people would like to "solve problems online" in order to acquire more routine in problem solving. More than three quarters like to "use a learning management system", 66\% would use "online help", and $63 \%$ find "online exams" of particular interest. Nearly everyone is familiar with the use of computers $(93.1 \%)$ and the internet $(95.8 \%)$. Altogether $91.7 \%$ can imagine themselves to learn with the use of a computer.

\section{Preparatory Courses and Personal Qualifications}

Finally, the target group was asked about their needs to bridge the gap between their qualification and the academic degree courses. The target group expects that they have to do some catching up mainly in mathematics $(58.2 \%)$ and programming $(53.9 \%)$, followed by physics $(41.85)$. Only $22.5 \%$ suppose that they will have problems to get along with basic concepts of electrical engineering. Asked whether they think that an approximate ratio of two days of face-to-face learning per month is sufficient, more than $70 \%$ of the respondents agreed. More than two thirds of the respondents can imagine doing so.

\section{EMPLOYERS' EXPECTATIONS}

\section{A. Study}

Another questionnaire was sent to human resources managers of 58 regional companies in Bavaria and Hesse in order to probe their view on the new study program and find out what they expected from the graduates. Between February and March 201224 questionnaires were returned, equivalent to a rate of $41 \%$. Most of the firms that took part in the study had more than 500 employees (71 $\%)$. This is the type of firm where most of the prospective students work indeed. Two thirds of the firms advise their personnel on continuing education. They focus on skilled workers with a proven record (54\%) followed by technicians $(31 \%)$, and master craftsmen (15\%). Unanimously, firms identify an age limit of 40 years for encouraging personnel to go for a Bachelor's degree. $58 \%$ of the firms are sure that they have candidates in their rows for the new study program; $36 \%$ do not know. Firms would grant students leave of absence to attend classes for up to 5 working days per semester $(75 \%)$ or offer them a reduction of their working hours without wage compensation $(54 \%)$; some firms ( $8 \%$ ) would even pay for compensatory wage increases when the student needs a reduction of working hours. The vast majority of firms (79 \%) are open to negotiating a contribution towards tuition fees.

\section{B. Engineers Needed}

$80 \%$ of the managers indicated that a Bachelor's degree is important or very important for a career in the company. Competencies that are strongly associated with engineers are: "being able to systematically solve complex problems", "thinking in contexts", and, with somewhat less emphasis, "ability for abstraction" and "better time management and self organization". The most valuable attribute of Bachelors of Engineering is the fact that "they bring fresh ideas, methods, and know-how with them". A broad knowledge base in electrical engineering is highly relevant for the firms. The next important abilities are experience in project management and the capacity to act as an engineer in design, simulation, measurement, and control. Being able to communicate in English is almost as important for firms. Special theoretical knowledge in electrical engineering is taken for granted. Management and personnel management rank at the end of the scale, and are the least important.

Industry needs engineers for development (15 indications), service (13), project management (11), production (10), application engineering (10) and quality management (10). Companies have their main areas of interest in automation (14), electronics (14), software engineering (13), and production technique (11). Therefore these specializations are preferred. The mentioned key aspects of activity are due to the industrial profile of the Main valley near Aschaffenburg.

\section{CONCLUSIONS}

The respondents can be viewed as typical of the target group addressed by the new Bachelor's program regarding their professional background and geographical distribution. Getting 144 people, mainly from Hesse and Bavaria, to answer a voluntary online survey within two months without any incentives indicates their interest in the subject. Overall, members of the target group seem to be very interested in further studies and course degree programs. Problems to be overcome are lacking monetary resources and obligations to their families. They seem to underestimate the support that they might get from their employers, as proven by the answers of regional firms to a corresponding question. The target group's desire to study is based on the assumption that an academic degree will help 
PAPER

A BACHELOR'S DEGREE IN ELECTRICAL ENGINEERING FOR NON-TRADITIONAL STUDENTS

them in their professional development and give them access to interesting tasks. This is confirmed by the human resources managers' answers in their questionnaire: Engineers are able to work on their own and solve complex technical problems. They may rightly expect to get promotion in their company having pursued a Bachelor's degree. A large number of target-group respondents are open to occupational change. This may be relevant for employers, who could use distance-learning programs as a means of staff development and as an instrument for binding personnel. Financial aid would be of great help for many non-traditional students. Companies are ready for negotiation. The political goal "upward mobility" seems to have reached the target group.

The target group is experienced in their job related to electrical engineering or technology. They have finished different vocational trainings (14 different answer categories), and, as a consequence, start with different previous knowledge. Hurdles for many non-traditional students might be deficits in mathematics and programming of which they are aware. Preparatory courses are important to bridge the gap. Online courses, material, and communication are suitable for the target group. They are used to computers and familiar with the internet.

\section{CONSEQUENCES FOR INSTRUCTIONAL DESIGN}

The instructional design was developed on the basis of the online survey's results, the experiences with the blended- and distance-learning Master's program, and the needs of the target group. In the following, we describe the corner stones for the Bachelor's program.

The potential non-traditional Bachelor's students have no experience in studying yet, quite contrary to the Master's students who have already acquired an academic degree. However, non-traditional students have hands-on experience in electrical engineering and may even be experts in a certain area. They need additional resources in several respects: They need to get familiar with the autonomy in learning expected in university studies. They need to organize themselves and their learning within their scarce time budget. They need to find out how to retrieve information efficiently. Therefore, an initial course will be offered to them, where they can learn studying techniques and will form teams with their classmates. This will support them in managing the initially new situation.

As to the missing basic knowledge in mathematics and programming, blended-learning preparatory courses will be offered beforehand. At the same time these courses are a chance for students to build learning teams right away from the start. Participation in these courses will be strongly recommended. The first students to test the preparatory study program will have the opportunity to strengthen their mathematics and programming knowledge from May 2013 on, coursework starting in the fall of 2013.

Since non-traditional students will remain employed, they need a reduced work load in their studies compared with full-time students. A work load of 20 credit points (European Credit Transfer System) instead of 30 credit points per semester is realistic, if course work and work as an employee are combined, e.g. through projects that may have interesting results for industry. Modules that build competencies in this area should be included in the study program for two reasons: They bring together many aspects of engineering, and help employed students to manage the often conflicting personal requirements. Learning material must be available independently of location and time so that the students can use it flexibly. There will be many different approaches to learning-time management. As a consequence students need to be able to choose times themselves. For efficiency, theses students need particular orientation and well structured material in the introductory courses. One should keep in mind that these students already have professional experience, and are somewhat older than the usual freshmen. Problems, formative evaluation and quizzes should offer them a means to judge their learning progress on their own. Support should be available, electronic media being an appropriate channel for this generation of students.

Regular attendance at university should be diluted to make it possible for students to combine working and studying. Classed need to be scheduled such that students can arrange their presence. Friday and Saturday seem natural choices taking into account that the target group lives within a distance of $200 \mathrm{~km}$ from Darmstadt or Aschaffenburg. It would certainly be helpful, if firms sponsored the students' efforts by granting them leave of absence. On the other hand, the time arrangement for being in class sparingly opens up room for students to fulfill family obligations.

With respect to the discussed requirements the following design has been chosen: A blended-learning Bachelor's program seems most appropriate, with online phases for self study, which will be supported by material on a learning management system. Lecture notes and additional e-learning offerings will be supplied to sustain learning. Phases of attendance will be restricted to four weekends per semester.

Communication and supervision are important for learners in a blended-learning setting. Accessibility beyond normal office hours is needed.

The outlined blended-learning Bachelor's degree will be probed in an experimental phase from fall 2013 to spring 2015.

\section{REFERENCES}

[1] www.wettbewerb-offene-hochschulen-bmbf.de

[2] A.L. Müller, R. Kurz, and B. Hoppe, "Development of a Distance Learning Concept for a Bachelor of Sciene in Electrical Engineering Programme", Procedia, Social and Behavioral Sciences, in press, available online at www.sciencedirect.com

[3] http://www.zfh.de

[4] H. Meuth, "Quality Assessment of the Master's Programme for Re-Accreditation", Darmstadt University of Applied Sciences 2011, unpublished

[5] A.L. Müller, B. Hoppe, A. Schwarzbacher, "Opening a M.Sc. in electrical engineering for non-traditional students", EDUCON 2012, IEEE Xplore

[6] A. Jürgens and B. Zinn, "Nichttraditionell Studierende in ingenieurwissenschaftlichen Studiengängen - Zugangswege, Motive, kognitive Voraussetzungen", Beiträge zur Hochschulforschung 34. Jahrgang, 4/2012, www.ihf.bayern.de 


\section{AUTHORS}

C. Böhmer is with the Hochschule Aschaffenburg, Aschaffenburg, Germany (e-mail: cornelia.boehmer@ hab.de).

N. Roznawski is with the Hochschule Aschaffenburg, Aschaffenburg, Germany (e-mail: nina.roznawski@ hab.de).

H. Meuth is with the Department Elektrotechnik Informationstechnik, Hochschule Darmstadt, Darmstadt, Germany, (e-mail: Hermann.meuth@ h-da.de).
E.M. Beck-Meuth is with the Fakultät Ingenieurwissenschaften, Hochschule Aschaffenburg, Aschaffenburg, Germany (e-mail: eva-maria.beck-meuth@ h-ab.de).

This article is an extended and modified version of a paper presented at the EDUCON2013 conference held at Technische Universität Berlin, Berlin, Germany from March 13-15, 2013. This work was supported in part by the Federal Ministry of Education and Research of the Federal Republic of Germany and the European Social Fund. Submitted14 May 2013. Published as re-submitteed by the authors 26 June 2013. 